\title{
Potencial antimicrobiano das nanopartículas de prata estabilizadas em curcumina e extrato de folhas de cajueiro (Anacardium occidentale $\mathbf{L}$.)
}

Antimicrobial potential of silver nanoparticles stabilized in curcumin and cashew leaf extract

(Anacardium occidentale L.)

Potencial antimicrobiano de nanopartículas de plata estabilizadas en curcumina y extracto de hoja de anacardo (Anacardium occidentale $\mathbf{L}$.)

Alciomar Veras Viana
ORCID: https://orcid.org/0000-0002-4928-5452
Centro Universitário UniFacid, Brasil
E-mail: alciomar@ naeon.org.br
Deuzuíta dos Santos Freitas Viana
ORCID: https://orcid.org/0000-0002-1902-6505
Centro Universitário Unifacid, Brasil
E-mail: deuzuitasfv@ gmail.com
Girlene Soares de Figueirêdo
ORCID: https://orcid.org/0000-0002-6710-1549
Universidade Federal do Piauí, Brasil
E-mail: girlenesf@ gmail.com
Josimar Elpídio de Brito
Centro Universitário UniFacid, Brasil
E-mail: josimarelpidio8@ gmail.com
Vicente Galber Freitas Viana
ORCID: htps $/ /$ ridid.org/000-0001-7323-5511
Instituto Federal de Educação, Ciência e Tecnologia do Piaú, Brasil
E-mail: galber@ifpi.edu.br
Vicente Galber Freitas Viana Junior
ORCID: https://orcid.org/0000-0002-3772-7751
Centro Universitário UniFacid, Brasil
E-mail: galber@ifpi.edu.br

\begin{abstract}
Resumo
A pesquisa teve como objetivo analisar o potencial antimicrobiano das nanopartículas de prata estabilizadas em curcumina e extrato de folhas de cajueiro (Anacardium occidentale L). Na metodologia as nanopartículas de prata (AgNPs) foram sintetizadas a partir de $125 \mathrm{~mL}$ de nitrato de prata $\left(\mathrm{AgNO}_{3}\right)$ em ebulição sob agitação magnética e gotejamento de $5 \mathrm{~mL}$ de citrato de sódio $1 \%$, e estabilizadas em curcumina e extrato de cajueiro. Os testes antimicrobianos foram realizados contra Staphylococcus aureaus, Escherichia coli, Candida albicans e Pseudomonas aeruginosa. O ensaio consistiu em dispersão do inóculo em toda a superfície das placas e posterior aplicação de discos contendo AgNPs na concentração de 1,0 mmol/L. Os halos formados foram mensurados com auxílio de um paquímetro em milímetros. Os resultados mostram que com as mudanças de coloração da solução na espectroscopia no ultravioleta visível UV-Vis, houve formação de AgNPs e indicaram atividade antimicrobiana contra cepas de Staphylococcus aureus. No entanto, não mostraram atividade inibitória contra a Pseudomonas aeruginosa e a Escherichia coli e também não apresentaram atividade inibitória de crescimento contra o fungo testado. Conclui-se que as AgNPs apresta potencial antimicrobiano contra Staphylococcus aureus. Portanto, devem ser testadas em outros microrganismos com outras concentrações, bem como ser aplicado em outras áreas tecnológicas e da saúde, como na regeneração tecidual.
\end{abstract}

Palavras-chave: Nanopartículas; Farmacorresistência bacteriana; Curcumina; Anacardium.

\begin{abstract}
The research aimed to analyze the antimicrobial potential of silver nanoparticles stabilized in curcumin and cashew (Anacardium occidentale L) leaf extract. In the methodology, silver nanoparticles (AgNPs) were synthesized from $125 \mathrm{~mL}$ of silver nitrate (AgNO3) at boiling under magnetic stirring and dripping with $5 \mathrm{~mL}$ of $1 \%$ sodium citrate, and stabilized in curcumin and cashew extract. Antimicrobial tests were performed against Staphylococcus aureaus, Escherichia coli, Candida albicans and Pseudomonas aeruginosa. The assay consisted of dispersing the inoculum
\end{abstract}


across the surface of the plates and subsequent application of discs containing AgNPs at a concentration of 1.0 $\mathrm{mmol} / \mathrm{L}$. The formed halos were measured with the aid of a caliper in millimeters. The results show that with changes in the color of the solution in visible ultraviolet UV-Vis spectroscopy, there was formation of AgNPs and indicated antimicrobial activity against Staphylococcus aureus strains. However, they did not show inhibitory activity against Pseudomonas aeruginosa and Escherichia coli and also did not show growth inhibitory activity against the tested fungus. It is concluded that AgNPs have antimicrobial potential against Staphylococcus aureus. Therefore, they must be tested on other microorganisms with other concentrations, as well as being applied in other technological and health areas, such as tissue regeneration.

Keywords: Nanoparticles; Bacterial drug resistance; Curcumin; Anacardium.

\section{Resumen}

La investigación tuvo como objetivo analizar el potencial antimicrobiano de nanopartículas de plata estabilizadas en extracto de hoja de curcumina y anacardo (Anacardium occidentale L). En la metodología se sintetizaron nanopartículas de plata (AgNPs) a partir de $125 \mathrm{~mL}$ de nitrato de plata (AgNO3) a ebullición bajo agitación magnética y goteo con $5 \mathrm{~mL}$ de citrato de sodio al $1 \%$, y se estabilizaron en curcumina y extracto de anacardo. Se realizaron pruebas antimicrobianas contra Staphylococcus aureaus, Escherichia coli, Candida albicans y Pseudomonas aeruginosa. El ensayo consistió en dispersar el inóculo por la superficie de las placas y posterior aplicación de discos que contenían AgNP a una concentración de $1.0 \mathrm{mmol} / \mathrm{L}$. Los halos formados se midieron con ayuda de un calibre en milímetros. Los resultados muestran que con cambios en el color de la solución en espectroscopía ultravioleta visible UV-Vis, hubo formación de AgNP y actividad antimicrobiana indicada contra cepas de Staphylococcus aureus. Sin embargo, no mostraron actividad inhibidora contra Pseudomonas aeruginosa y Escherichia coli y tampoco mostraron actividad inhibidora del crecimiento contra el hongo probado. Se concluye que los AgNP tienen potencial antimicrobiano contra Staphylococcus aureus. Por tanto, deben ensayarse sobre otros microorganismos con otras concentraciones, así como aplicarse en otras áreas tecnológicas y sanitarias, como la regeneración de tejidos.

Palabras clave: Nanopartículas; Resistencia a fármacos bacterianos; Curcumina; Anacardium.

\section{Introdução}

A resistência dos microrganismos patogênicos aos fármacos possui implicações diretas à segurança dos pacientes em internações hospitalares. Prolonga a estadia do paciente no hospital, aumenta a necessidade do uso de antibióticos de longo espectro e os riscos de evoluir ao óbito, principalmente pela ausência de terapêutica alternativa. Considerando a resistência bacteriana uma epidemia com graves consequências, estima-se que a partir do ano de 2050 as infecções por bactérias resistentes sejam responsáveis em média, pela morte de dez milhões de pacientes por ano (Mello \& Oliveira, 2021).

Como alternativa contra os microrganismos multirresistentes, utilização de nanopartículas na medicina tornou-se uma das principais subcategorias da nanotecnologia ganhando o nome de Nanomedicina. O rápido e dinâmico avanço da medicina permitiu incorporar os nanomateriais aos meios biológicos, dando origem a novas formas de diagnóstico e tratamento de diversas patologias. Estas possibilidades de aplicação ganha cada vez mais expressividade no meio médico (Sharma et al., 2019).

A síntese das nanopartículas pode ocorrer através de três mecanismos: de "cima para baixo" (top to botton), de "baixo para cima" (botton to top) e síntese verde. O método de "cima para baixo" constitui na formação de nanopartículas através de técnicas físicas de redução de tamanho, como pulverização, ablação térmica e lazer. Essa técnica está relacionada com produção de nanopartículas variadas em tamanho e geometria, assim como quantidade significativa de impurezas e defeitos (Mathur et al., 2018).

A aplicação bem sucedida das nanopartículas despertou o interesse de diversos ramos da ciência Dentre eles podem citar a nanoeletrônica, diagnóstico por imagem, molecular e biomedicina. Além de apresentam atividade antiplaquetária, antitumoral, antiviral e antifúngica apresenta ação cicatrizante, anti-inflamatória e atividade antimicrobiana contra bactérias como Staphylococcus aureus, Escherichia coli (de Brito et al., 2021).

Atualmente, existem várias discussões sobre os mecanismos nos quais as nanopartículas de prata exercem seu efeito antibacteriano. Dentre elas, Duràn (Durán, 2019) explicam que a grande área de contato com a bactéria facilita a invasão das 
nanopartículas, e estas, por sua vez, interferem na respiração celular realizada pelas mitocôndrias bacterianas ocasionando sua morte. Esta ação está diretamente relacionada ao potencial de superar mecanismos de resistências aos antibióticos já existentes, à múltipla ação inibitória, e à capacidade de transportar antibióticos (Da Silva \& Aquino, 2018).

Quanto aos mecanismos antimicrobianos sugere que ação bactericida das nanopartículas de prata está relacionada a vários fatores como, o formato, tamanho, concentração e estado coloidal. Em relação ao formato, a maior reatividade está relacionada diretamente com o número de facetas da partícula, o que justifica partículas triangulares apresentarem maior ação antimicrobiana em relação às esféricas. Para que haja ação efetiva, o tamanho da nanopartícula não deve ultrapassar o limite de $50 \mathrm{~nm}$, contudo medidas de 10-15 nm associam-se a maior estabilidade, biocompatibilidade, e também, maior ação antimicrobiana (Freire Naiana,. Pires, Larissa, Oliveira, Helinando, Costa, 2018).

A presença de compostos ativos nas plantas facilita a estabilização das nanopartículas. Entre estes compostos estão os flavonoides, apigenina, kanferol, quercetina e agastiflavona encontrados no cajueiro (Anacardium occidentale L.), planta nativa do Brasil com característica dos campos e das regiões costeiras do Norte e Nordeste (Novaes e Novaes, 2021). Outro composto usual é a curcumina, um polifenol presente no rizoma da planta (Curcuma longa) com ação antioxidante, antimicrobiana, anticoagulante e anticâncer (Carneiro \& Macedo, 2020).

O potencial terapêutico das plantas medicinais tem despertado grande interesse nas últimas décadas, em aplicações na aérea de saúde. Hoje cerca de $30 \%$ das drogas prescritas no mundo são obtidas direta ou indiretamente de plantas. Entre o período de 1981 a 2002, 50\% das drogas desenvolvidas foram obtidas a partir de produtos naturais, análogos semissintéticos ou ainda compostos sintéticos baseados em produtos naturais (Macêdo et al., 2018).

No entanto, as cepas de $S$. aureus, apresentou diferença significativa com concentração de $7.50 \mu \mathrm{g} / \mathrm{mL}$, sugerindo que concentrações maiores apresentam efeito inibidor maior, principalmente em bactérias Gram positivas. Já a concentração de $1.50 \mu \mathrm{g} / \mathrm{mL}$ de nanopartículas de prata foi capaz de inibir cepas de $S$. aureus e Escherichia coli, (Brito \& Ferraz, 2019). Houve também, inibição de crescimento de Staphylococcus aureus, Escherichia coli, e Staphylococcus epidermitis (Cruz FJA et al., 2016).

A ação inibitória das nanopartículas de prata (AgNPs) contra microrganismos patogênicos foi observado contra Staphylococcus aureus resistente a meticilina (MRSA), com ênfase nas nanopartículas de $20 \mathrm{~nm}$ de tamanho. In vitro contra bactérias Gram-negativas com múltiplos mecanismos de resistência, dentre eles, Enterobacteria portadora de carbapenemase (KPC), Acinetobacter portadora de oxacilinases, e Pseudomonas aeruginosa portadora de metalo-beta-lactamases (Freire et al., 2018).

O potencial bactericida das AgNPs, também foi observado in vivo em coelhos utilizando implantes 316L SS depositados no nanopartículas. Verificou que as nanopartículas de prata apresentam efeito inibitório sobre o crescimento e multiplicação de outros agentes patogênicos como Bacillus subtilis, Salmonella typhimurium, Pseudomonas aeruginosa e Klebsiella pneumoniae (Santos \& Secoli, 2019).

As nanopartículas de prata (AgNPs) sintetizadas a partir de nitrato de prata $\left(\mathrm{AgNO}_{3}\right)$, apresentam também propriedade antifúngica e antiviral, atividade inibitória contra o vírus influenza A (H1N1), adenovírus tipo 3, vírus influenza A (H7N3) (Fatima et al., 2016), Chikungunya (Sharma et al., 2019) e vírus herpes simplex e alta sensibilidade das leveduras Candida albican e Candida tropicalis pelas AgNPs (Akbarzadeh et al., 2018).

Diante do potencial antimicrobiano da curcumina (Sabir et al., 2021), do extrato de cajueiro (Silva et al., 2021) e das nanopartículas de prata (Orellano P, et al., 2021) já descrito na literatura a pesquisa tem como objetivo analisar o potencial antimicrobiano das nanopartículas de prata estabilizadas em curcumina e extrato de folhas de cajueiro (Anacardium occidentale L). 


\section{Metodologia}

A pesquisa em questão é do tipo laboratorial, de natureza quantitativa, adotou a observação de fenômenos e analisou os elementos encontrados com a finalidade de estabelecer relações entre eles (Pereira et al., 2018).

O experimento foi realizado de setembro de 2020 a março de 2021 conforme as normas técnicas do decreto 93.933 de 14/01/1987 em laboratório básico de microbiologia, e foi utilizado microorganismos de grupo de risco I e II. Para obtenção do extrato de cajueiro as folhas foram secas e depois trituradas até se obter $200 \mathrm{~g}$ de pó grosso, este foi amassado em álcool (70\%) em proporção soluto/solvente de 1:5 por 24 horas. Depois o extrato hidroalcoólico de caju foi filtrado usando um funil de algodão quatro vezes, e por fim foi centrado em baixa pressão obtendo-se o extrato seco. A curcumina foi obtida em uma farmácia de manipulação local e utilizada na concentração de 0,0368 mol/L a $100 \mathrm{~mL}$ de álcool, como um estabilizante na síntese das nanopartículas de prata.

Para o preparo da solução de nanopartículas de prata, $125 \mathrm{~mL}$ de nitrato de prata 1,0 mmol/L foi aquecida em agitação magnética numa chapa aquecedora até entrar em ebulição. Atingida a temperatura de ebulição, foi misturado gota a gota 5 mL de citrato de sódio $1 \%$ na solução de nitrato de prata. O gotejamento ocorreu numa taxa de 1 gota por segundo, sob aquecimento e agitação magnética.

A mistura foi mudando de cor até atingir a coloração amarelado. Essa coloração indica a redução da prata com formação de nanopartículas. Após atingir essa coloração, foi desligado o aquecimento da chapa aquecedora. No entanto, a solução foi mantida em agitação magnética. A solução contendo as nanopartículas após atingirem a temperatura ambiente (25 graus célsius), foi adicionado o extrato vegetal previamente produzida. Após 15 minutos, as soluções de nitrato de prata/citrato/curcumina e nitrato de prata/citrato/acaju foram acondicionadas em frascos âmbar.

Depois da síntese, as nanopartículas de prata foram caracterizadas por espectroscopia infravermelho e UV-Vis Os espectros de absorção UV-Visível das amostras de nanopartícula de prata, foram obtidos pelo uso do equipamento (UV Spectrophotometer UV-1800 SHIMADZU), em cubetas de quartzo com tampa, de 1 cm de caminho óptico. Para a determinação dos espectros, foi utilizado o intervalo de varredura de 800nm a 190nm, com tempo de integração de 0,5 segundos, em 1 - metil 2-pirrolidona puro e com o branco.

Os testes de verificação de atividade antimicrobiana da AgNPs foram realizados contra cepas microbiano padrão. Sendo uma espécie bacteriana gram-positiva, Staphylococcus aureus ATCC 25923, uma espécie gram-negativa, Escherichia coli ATCC 25922, e uma espécie de fungo leveduriforme, Candida albicans ATCC 10231. Além das cepas padrão, também se determinou a atividade antimicrobiana do referido composto contra uma cepa de Pseudomonas aeruginosa.

As cepas bacterianas foram mantidas em tubos contendo ágar Brain Infusion Heart (BHI, Himedia, Índia) inclinados a $4{ }^{\circ} \mathrm{C}$, e antes do ensaio as células foram cultivadas durante uma noite a $37^{\circ} \mathrm{C}$ em Brain Heart Infusion (BHI, Himedia, Índia). O ágar Sabouraud Dextrose foi usado tanto para manutenção da cepa de levedura como para o cultivo das células.

O inóculo das espécies microbianas a serem testadas foi padronizado pelo método de suspensão direta das colônias CLSI (2009) em solução salina esterilizada. Todas as culturas semeadas foram incubadas à temperatura de $37^{\circ} \mathrm{C}$ em estufa de crescimento. Por meio de uma alça de platina esterilizada realizou-se a inoculação dos micro-organismos repicados, em tubos de ensaio com $1 \mathrm{ml}$ de soro fisiológico a $0,9 \%$. A suspensão de células foi ajustada a concentração de $1 \times 10^{8} \mathrm{UFC} / \mathrm{mL}$, que corresponde a solução padrão de McFarland de 0,5.

Para a determinação da atividade antimicrobiana das substâncias frente às cepas microbianas, utilizou-se o método preconizado por Bauer e colaboradores (1966) com adaptações. O ensaio consiste na aplicação do inóculo utilizando um swab esterilizado em toda a superfície de uma placa de Petri de $45 \mathrm{~mm}$ com meio ágar Muller Hinton. Posteriormente, foram adicionados discos contendo AgNPs na concentração de 1,0 mmol/L. Em seguida, as placas foram incubadas por um período 
de 24 horas em estufa de crescimento bacteriológico, em temperatura de $37^{\circ} \mathrm{C}$. Cada experimento foi realizado em triplicata. Após o período de incubação, os halos de inibição do crescimento microbiano ao redor de cada disco foram mensurados com auxílio de um paquímetro em milímetros.

Após a síntese das nanopartículas é importante realizar a sua caracterização porque, alterações na forma ou tamanho das nanopartículas implicam nas atividades biológicas que desempenharão. Dentre as características físico-químicas relevantes para o estudo das nanopartículas pode citar tamanho, propriedades da superfície, forma, composição, peso molecular, identidade, pureza, estabilidade e solubilidade (Telles, et al., 2017).

\section{Resultados}

O resultado mostrou a formação de nanopartículas de prata AgNPs, a partir no nitrato de prata $\left(\mathrm{AgNO}_{3}\right)$ como material de partida, citrato como agente redutor e a curcumina e extrato de cajueiro (Anacardium occidentale) como agentes estabilizadores. Durante a síntese e estabilização das nanopartículas de prata foi possível observar a mudança de coloração, essa mudança ocorre devido ao fenômeno de ressonância plasmônica e o efeito de confinamento quântico de superfície. Isto ocorre por conta da excitação coletiva de elétrons na interface entre um condutor e um isolante (Figura 1).

Figura 1 - Síntese das nanopartículas de prata.
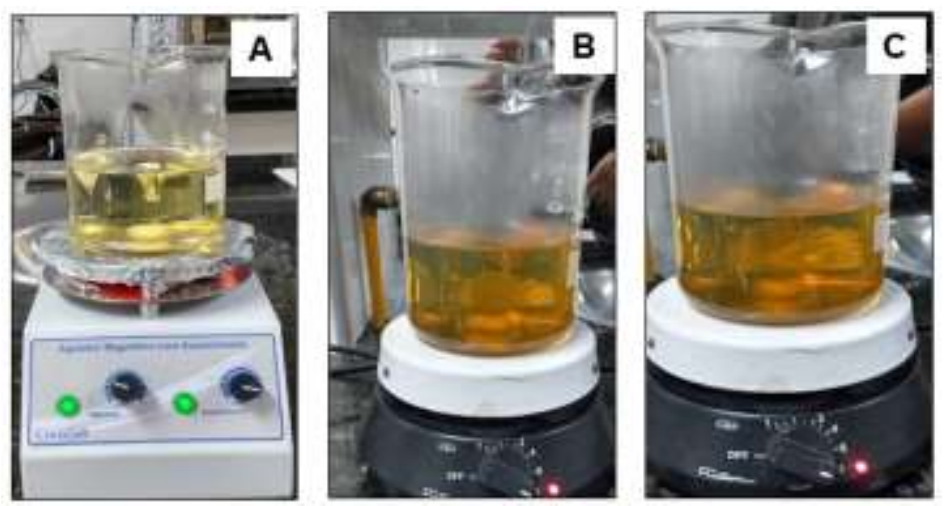

Fonte: Autores (2021).

Através do espetro de UV-Vis é possível analisar as nanopartículas. A partir das medidas de absorbância e dos valores da concentração de prata nas soluções foi possível construir a curva analítica. Para as nanopartículas de prata a ressonância ocorre na região da luz visível, fato que faz com que a solução apresente coloração característica. Conforme o espectro de absorção plasmons dos compostos sintetizados, notou-se que o comprimento de onda de máxima absorção está localizado em aproximadamente 400nm. Tal evidência concerne com a formação de nanopartículas de prata em formato esférico (Figura 2). 
Figura 2 - Espectro de absorção na região do Infravermelho referente às soluções de curcumina/citrato/nanopartícula de prata e cajueiro/citrato/nanopartículas de prata.
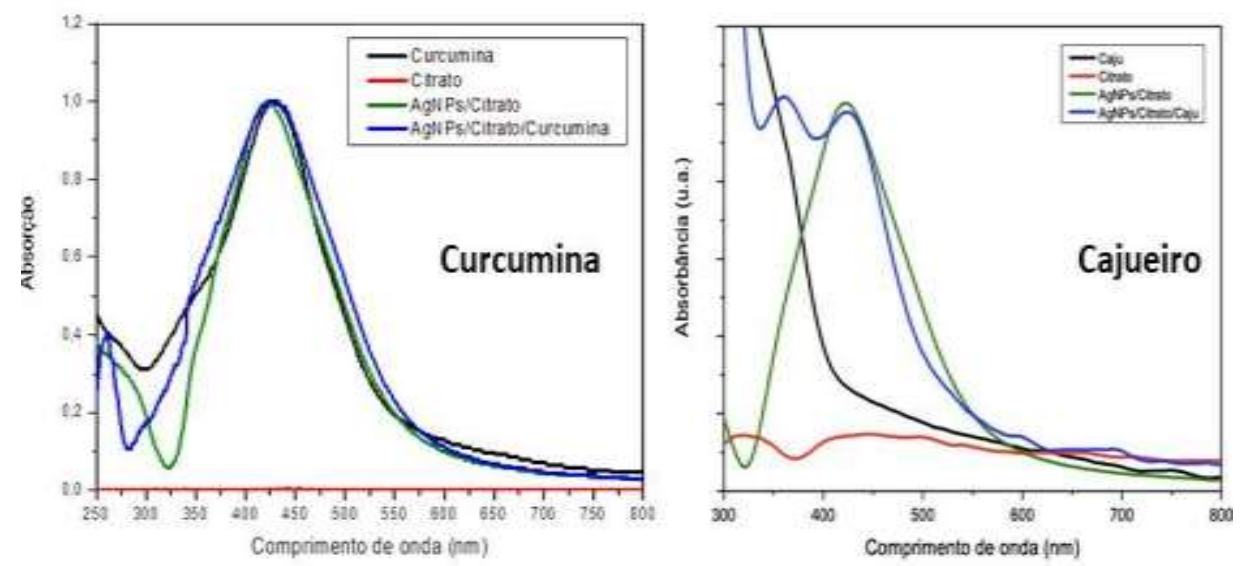

Fonte: Autores (2021).

As nanopartículas de prata sintetizadas e caracterizadas por meio do espectro de absorção utilizando espectrometria UV-Vis em uma faixa de comprimento de onda entre 250 e $800 \mathrm{~nm}$, apresentaram picos com uma banda nítida entre 420430nm e 410-430, respectivamente, compatível com as excitações dos plasmons de superfície, semelhantes aos trabalhos de (Rani et al., 2020).

A relação de UV-Vis para as duas análises (Figura 2), aponta que a síntese de AgNPs em curcumina e cajueiro apresentaram um pico de absorção em 400nm-450nm, atribuída a Ressonância Plasmônica de Superfície (SPR) ou oscilação ressonante dos elétrons nas AgNPs na presença de luz. Os dois extratos analisados indicam ser eficientes para a síntese de AgNPs. O pico máximo e único de absorção na faixa SPR em 420nm indica tamanho aproximado de 20nm e formato esférico (Rani et al., 2020). Embora em cajueiro comprimento de onde tenha sido mais longa.

A ação contra Staphylococcus aureus das soluções (1) AgNPs + citrato + curcumina; (2) AgNPs + citrato e (3) curcumina apresentaram a formação de halos de inibição de diâmetro de $10 \mathrm{~mm}$ para estas substâncias (Figura 3a).

A ação contra Staphylococcus aureus das soluções (4) AgNPs + citrato + cajueiro; (5) AgNPs + citrato e (6) cajueiro foi menor quando comparadas às substancia 1, 2 e 3 formando halos de inibição de 8 mm para todas as substâncias (Figura 3b).

Figura 3 - Teste de difusão em discos contra Staphylococcus aureus.
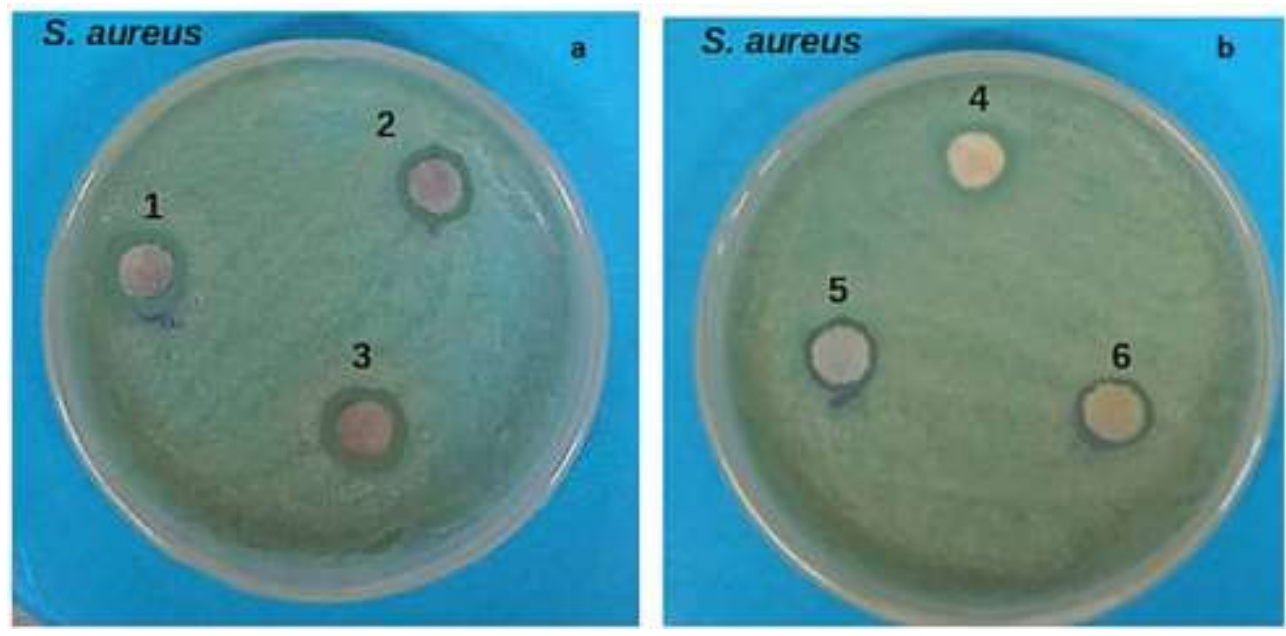

Fonte: Autores (2021). 


\section{Discussão}

Materiais em escala nanométrica apresentam novas propriedades e comportamentos diferentes daquelas que geralmente apresentam em escala macroscópica. As propriedades dos materiais são fortemente dependentes do tamanho das partículas deste material. As propriedades óticas, elétricas, magnéticas, de transporte, catalíticas entre outras dos materiais manifestam-se a partir de um determinado tamanho, chamado de crítico. Este fato sugere que a evolução da nanotecnologia é considerada uma das constituintes da Quarta Revolução Industrial (Huffer; Lazzaretti, 2019).

A síntese verde como técnica de redução e estabilização de nanopartículas é preferível devido ao baixo custo, capacidade de produção em larga escala e pouco dano ao meio ambiente, realizada com o auxílio de produtos naturais como extrato vegetal e microrganismos (Mathur, et al., 2018). Como visto, os resultados encontrados convergem com diversos autores que afirmam ser possível produzir extratos com atividades redutoras e estabilizadoras dispensando, dessa forma, o uso de solventes mais tóxicos e consequentes nocivos ao meio ambiente e aos seres vivos (Álvarez et al., 2017).

A síntese verde das nanopartículas de prata utilizando plantas e a possibilidade que essa abordagem de síntese proporciona, só é possível porque os extratos vegetais apresentam compostos fitoquímicos capazes de recobrir e estabilizá-las as nanopartículas. No entanto, essa estabilidade no processo de síntese pode ser afetada por diferentes fatores, como pela espécie do solvente ou pela quantidade de agentes redutores (Houllou et al., 2019).

A utilização de extratos de plantas para a síntese da nanopartícula, com base nos conceitos de química verde, se beneficie dos compostos ativos presentes nas estruturas vegetais que facilitam a redução e estabilização. Dentre as plantas ricas nestes compostos encontra-se o cajueiro (Anacardium occidentale L.), planta nativa do Brasil com característica dos campos e das regiões costeiras do Norte e Nordeste. Considera-se que o potencial antimicrobiano da planta se dá pela ação dos lipídeos fenólicos, flavonoides, apigenina, kanferol, quercetina e agastiflavona que possibilitam a estabilização das nanopartículas e fixação em sua superfície (Novaes \& Novaes, 2021).

Os parâmetros para formação nanopartículas de prata, dependem da natureza dos materiais como concentração do nitrato de prata, concentração dos extratos vegetais, duração e temperatura do processo de síntese, entre outros. Estes fatores influenciam no tempo necessário para que ocorra a mudança da coloração das suspensões, bem como a intensidade dessas (Boriollo, et al., 2020).

A ação bactericida das nanopartículas de prata está relacionada a vários fatores, como o formato, tamanho, concentração e estado coloidal. Em relação ao formato, a maior reatividade está relacionada diretamente com o número de facetas da partícula, o que justifica partículas triangulares apresentarem maior ação antimicrobiana em relação às esféricas (Fatima, et al., 2016).

No estudo de De Brito e Ferraz (2019) observou que concentrações de $1.50 \mu \mathrm{g} / \mathrm{mL}$ de nanopartículas de prata foram capazes de inibir cepas de S. aureus e Escherichia coli. No entanto, as cepas de S. aureus, apresentou diferença significativa com concentração de $7.50 \mu \mathrm{g} / \mathrm{mL}$, sugerindo que concentrações maiores apresentam efeito inibidor maior, principalmente em bactérias Gram positivas. Este estudo converge com nossos resultados em relação S. aureus e diverge em relação à Escherichia coli, fato que sugere testar outras concentrações das soluções utilizadas.

A curcumina é um composto ou um ingrediente presente no rizoma da planta (Curcuma longa) é um polifenol amplamente usado como corante natural tem ação antioxidante, antimicrobiana, anticoagulante e anticâncer (Carneiro JA; Macedo, 2020). Devido estas ações é muito usada em diversas atividades farmacológicas (Sabir et al., 2021). Os grupos fenólicos, $\beta$-dicetana e metila presentes na curcumina, além de ter um efeito autorregulador (Judaki et al., 2017) podem tem a capacidade de reduzir e estabilizar nanopartículas da prata a partir do nitrato de prata. 
A síntese de nanopartículas a base do extrato de folhas de cajueiro, um produto natural, pode apresentar em princípio propriedades biocompatíveis permitindo sua utilização como antimicrobiano. Essas possíveis bioaplicações se apoiam no fato da planta já ser usada na medicina popular, como antiparasitário, antiespasmódico, anti-inflamatório e antibactericida em tratamento de infecção em animais e humanos (Padilha et al., 2020).

Ação contra Candida albicans nenhuma das substâncias avaliadas apresentou formação de halos de inibição do crescimento. Enquanto, (Jo et al., 2009) observou em sua pesquisa inibição significativa da formação de colônias de dois fungos patogênicos em planta, indicando alta sensibilidade das leveduras Candida albican e Candida tropicalis pelas AgNPs, esses dois fungos estão bem relacionados com infecções hospitalares.

Observou-se ainda no estudo de (Freire, et al., 2018) boa atividade in vitro das AgNPs contra bactérias Gramnegativas com múltiplos mecanismos de resistência, dentre eles Enterobacteria, Acinetobacter e Pseudomonas aeruginosa. A divergência entre as pesquisas pode está relacionada a vários fatores, como o formato, tamanho, concentração e estado coloidal, quando ao formato, a maior reatividade está relacionada diretamente com o número de facetas da partícula, o que justifica partículas triangulares apresentarem maior ação antimicrobiana em relação às esféricas.

A resistência aos antimicrobianos é resultado das mutações gênicas e da transferência horizontal de genes de resistência que ocorrem principalmente no meio ambiente. Esses mecanismos estão relacionados à resistência antimicrobianas clinicamente relevantes. Assim, o desenvolvimento e o aumento de bactérias resistentes podem ocorrer divido a exposição aos antibióticos em diferentes lugares como entre os seres humanos na comunidade e nos hospitais ou na própria natureza(Sharma V, et al., 2019).

Dessa forma compreende-se que as nanopartículas de prata constituem opções promissoras na linha de defesa contra infecções multirresistentes. Essa relevância médica está diretamente relacionada ao potencial de superar mecanismos de resistências aos antibióticos já existentes, à múltipla ação inibitória, e à capacidade de transportar antibióticos (Machado EC, et al., 2020).

\section{Conclusão}

Nesta pesquisa foram desenvolvidas e estabilizadas nanopartículas de prata, com aspecto visual de cor amarelada, de forma esférica e dimensão em torno de 20nm a partir da utilização de dois diferentes extratos de origem vegetal a curcumina e o extrato de folhas de caju (Anacardium occidentale). As nanopartículas obtidas com extrato de curcumina formaram um pico bem definido e menor comprimento de onda. Já o pico formado na síntese utilizando extrato de cajueiro, teve menor definição e onda mais alargada. Com estes resultados conclui-se que os extratos vegetais se mostraram eficientes no desenvolvimento e estabilização das nanopartículas por meio da síntese verde. As AgNPs indicam atividade antimicrobiana contra cepas de Staphylococcus aureus. No entanto, não mostraram atividade inibitória contra a Pseudomonas aeruginosa, Escherichia coli e o fungo testado. Conclui-se que as AgNPs desenvolvidas na pesquisa apresentam como uma opção promissora no combate à resistência bacteriana, devendo se ser testadas em outros microrganismos com outras concentrações.

\section{Referências}

Akbarzadeh, A., Kafshdooz, L., Razban, Z., Dastranj Tbrizi, A., Rasoulpour, S., Khalilov, R., Kavetskyy, T., Saghfi, S., Nasibova, A. N., Kaamyabi, S., \& Kafshdooz, T. (2018). An overview application of silver nanoparticles in inhibition of herpes simplex virus. Artificial Cells, Nanomedicine, and Biotechnology, 46(2), 263-267. https://doi.org/10.1080/21691401.2017.1307208

Álvarez, A., Poejo, J., Matias, A. A., Duarte, C. M. M., Cocero, M. J., \& Mato, R. B. (2017). Microwave pretreatment to improve extraction efficiency and polyphenol extract richness from grape pomace. Effect on antioxidant bioactivity. Food and Bioproducts Processing, 106, 162-170. https://doi.org/10.1016/j.fbp.2017.09.007 
Boriollo, M. F. G., Alves, V. E., Silva, T. A., Silva, J. J., Barros, G. B. S., Dias, C. T. S., Höfling, J. F., \& Oliveira, N. M. S. (2020). Decrease of the DXRinduced genotoxicity and nongenotoxic effects of Theobroma cacao revealed by micronucleus assay. Brazilian Journal of Biology. https://doi.org/10.1590/1519-6984.223687

Brito, J. E. de, Paranhos, C. N., Viana, D. dos S. F., Nunes, J. L., \& Cavalli, L. C. G. (2021). Genotoxicidade das nanoestruturas aplicadas em saúde: Uma revisão integrativa. Revista Eletrônica Acervo Saúde, 13(3), e6298. https://doi.org/10.25248/reas.e6298.2021

Carneiro, J. A., \& Macedo, D. S. (2020). Curcuma: Princípios Ativos e seus benefícios para a saúde. p., $14(87), 9$.

Cruz, F. J. A., et al (2016). Evaluación de la actividad antibacteriana y moduladora de los Extractos metanol y Hexano de la Hoja de Allium cepa. Ciencias de la Salud, 14(2), 191-200. https://doi.org/10.12804/revsalud14.02.2016.04

Da Silva, M. O., \& Aquino, S. (2018). Resistência aos antimicrobianos: Uma revisão dos desafios na busca por novas alternativas de tratamento. Revista de Epidemiologia e Controle de Infecção, 8(4), 472-482. https://doi.org/10.17058/reci.v8i4.11580

de Brito, A. S., e Ferraz, R. R. N. (2019). Importância Dos Probióticos No Equilíbrio Da Microbiota Intestinal De Recém-Nascidos: Síntese De Evidências. Revista Saúde em Foco, 9

Durán, A. B., Nelson, R., Wallace, R., Durán, M., \& Fávaro, W. J. Seabra. (2019). Nanotoxicologia De Nanopartículas De Prata: Toxicidade Em Animais E Humanos. Química Nova, 42, 206-213. http://www.scielo.br/scielo.php?script=sci_arttext\&pid=S0100-40422019000200206\&lang=pt

Fatima, M., Zaidi, N.-S. S., Amraiz, D., e Afzal, F. (2016). In Vitro Antiviral Activity of Cinnamomum cassia and Its Nanoparticles Against H7N3 Influenza A Virus. Journal of Microbiology and Biotechnology, 26(1), 151-159. https://doi.org/10.4014/jmb.1508.08024

Freire, M. M., Naiana B., Pires, Larissa C. S. R., Oliveira, \& Helinando P. C. (2018). Atividade antimicrobiana e antibiofilme de nanopartículas de prata sobre isolados de Aeromonas spp. Obtidos de organismos aquáticos. Pesquisa Veterinária Brasileira, 38, 244-249. http://www.scielo.br/scielo.php?script=sci_arttext\&pid=S0100-736X2018000200244\&lang=pt

Freire, N. B., Pires, L. C. S. R., Oliveira, H. P., \& Costa, M. M. (2018). Atividade antimicrobiana e antibiofilme de nanopartículas de prata sobre isolados de Aeromonas spp. Obtidos de organismos aquáticos. Pesquisa Veterinária Brasileira, 38(2), 244-249. https://doi.org/10.1590/1678-5150-pvb-4805

Houllou, L. M., De Souza, R. A. B., Malafaia, C. B., Paixão, D. L. M. da, Araújo, A. T. B. de, Silva, M. G., \& Duarte, G. C. S. (2019). Green synthesis of silver nanoparticles using leaf extract from Tabebuia roseoalba and T. pentaphylla. Journal of Environmental Analysis and Progress, 216-222. https://doi.org/10.24221/jeap.4.3.2019.2523.216-222

Hupffer, H. M., \& Lazzaretti, L. L. (2019). Nanotecnologia E Sua Regulamentação No Brasil. Revista Gestão e Desenvolvimento, 16(3), 153. https://doi.org/10.25112/rgd.v16i3.1792

Jo, Y.-K., Kim, B. H., \& Jung, G. (2009). Antifungal Activity of Silver Ions and Nanoparticles on Phytopathogenic Fungi. Plant Disease, 93(10), 1037-1043. https://doi.org/10.1094/PDIS-93-10-1037

Judaki, A., Rahmani, A., Feizi, J., Asadollahi, K., \& Hafezi Ahmadi, M. R. (2017). Curcumin In Combination With Triple Therapy Regimes Ameliorates Oxidative Stress And Histopathologic Changes In Chronic Gastritis-Associated Helicobacter Pylori Infection. Arquivos de Gastroenterologia, 54(3), 177-182. https://doi.org/10.1590/s0004-2803.201700000-18

Macêdo, M. J. F., Ribeiro, D. A., Santos, M. de O., Macêdo, D. G. de, Macedo, J. G. F., Almeida, B. V. de, Saraiva, M. E., Lacerda, M. N. S. de, \& Souza, M. M. de A. (2018). Fabaceae medicinal flora with therapeutic potential in Savanna areas in the Chapada do Araripe, Northeastern Brazil. Revista Brasileira de Farmacognosia, 28(6), 738-750. https://doi.org/10.1016/j.bjp.2018.06.010

Machado, E. C., Leal, C. D., Coelho, B. L., Chernicharo, C. A. de L., \& Araújo, J. C. de. (2020). Detecção e quantificação de bactérias resistentes aos antibióticos ampicilina e cloranfenicol em estações de tratamento de esgoto doméstico. Engenharia Sanitaria e Ambiental, $25(6)$, 847-857. https://doi.org/10.1590/s1413-4152202020180001

Mathur, P., Jha, S., Ramteke, S., e Jain, N. K. (2018). Pharmaceutical aspects of silver nanoparticles. Artificial Cells, Nanomedicine, and Biotechnology, 46(sup1), 115-126. https://doi.org/10.1080/21691401.2017.1414825

Mello, M. S. de, \& Oliveira, A. C. (2021). Overview of the actions to combat bacterial resistance in large hospitals. Revista Latino-Americana de Enfermagem, 29, e3407. https://doi.org/10.1590/1518-8345.3952.3407

Novaes, T. E. R., \& Novaes, A. S. R. (2021). Análise dos potenciais medicinais do cajueiro (Anacardium occidentale Linn): Uma breve revisão. Research, Society and Development, 10(1), e41810111838. https://doi.org/10.33448/rsd-v10i1.11838

Orellano, P., González, A., Vucovich, L., \& Peirano, V. (2021). Nanopartículas de plata en el tratamiento de la micosis asociada al pie diabético. 9. https://doi.org/doi: 10.29193/RMU.37.1.6

Padilha, J. A., Vieira, L. N., Magalhães, V. F., Edson, R., \& Reginato, D. (2020). Therapeutic effects of Anacardium occidentale: An integrative review. Acta Brasiliensis, 9 .

Pereira A. S, Shitsuka D. M, Parreira F. J, e Shitsuka R. (2018). Metodologia da pesquisa científica. UFSM https://repositorio.ufsm.br/bitstream/handl e/1/15824/Lic_Computacao_Metodologia-Pesquisa -Cientifica.pdf?sequence=1.

Rani, P., Kumar, V., Singh, P. P., Matharu, A. S., Zhang, W., Kim, K.-H., Singh, J., \& Rawat, M. (2020). Highly stable AgNPs prepared via a novel green approach for catalytic and photocatalytic removal of biological and non-biological pollutants. Environment International, 143, 105924. https://doi.org/10.1016/j.envint.2020.105924 
Research, Society and Development, v. 10, n. 9, e47610918364, 2021

(CC BY 4.0) | ISSN 2525-3409 | DOI: http://dx.doi.org/10.33448/rsd-v10i9.18364

Sabir, S. M., Zeb, A., Mahmood, M., Abbas, S. R., Ahmad, Z., \& Iqbal, N. (2021). Phytochemical analysis and biological activities of ethanolic extract of Curcuma longa rhizome. Brazilian Journal of Biology, 81(3), 737-740. https://doi.org/10.1590/1519-6984.230628

Santos, W. M. dos, \& Secoli, S. R. (2019). Economic burden of inpatients infected with Klebsiella pneumoniae carbapenemase. Einstein (São Paulo), 17(4), eGS4444. https://doi.org/10.31744/einstein_journal/2019GS4444

Sharma, V., Kaushik, S., Pandit, P., Dhull, D., Yadav, J. P., \& Kaushik, S. (2019). Green synthesis of silver nanoparticles from medicinal plants and evaluation of their antiviral potential against chikungunya virus. Applied Microbiology and Biotechnology, 103(2), 881-891. https://doi.org/10.1007/s00253018-9488-1

Silva, I. D. de L., Oliveira, F. S. M. de, Andrade, M. F. de, Brito, A. M. S. S., Hallwass, F., \& Vinhas, G. M. (2021). Avaliação das potencialidades dos extratos vegetais de jurema preta (Mimosa tenuiflora) e cajueiro (Anacardium occidentale L.) para uso em embalagens ativas antimicrobianas e antioxidantes. Matéria (Rio de Janeiro), 26(1), e12924. https://doi.org/10.1590/s1517-707620210001.1224

Telles, I. S. F., Prado, M. D., \& Simão, R. A. (2017). Nanopartículas e aplicações endodônticas: Uma revisão da literatura. Revistas, 74(2), 167. https://doi.org/10.18363/rbo.v74n2.p.167 